\title{
Mild cooling of the feet does not aid night-time vigilance
}

\author{
Ryan Sixtus ${ }^{1}$, Barbara C Galland², James D Cotter ${ }^{1 *}$ \\ From 15th International Conference on Environmental Ergonomics (ICEE XV) \\ Portsmouth, UK. 28 June - 3 July 2015
}

\begin{abstract}
Introduction
Vigilance is related to core temperature $\left(\mathrm{T}_{\mathrm{C}}\right)$ and skin temperature $\left(\mathrm{T}_{\text {sk }}\right)$. Biological day reflects a high $\mathrm{T}_{\mathrm{C}}$, alertness and modest $\mathrm{T}_{\mathrm{sk}}$; night reflects vice versa $[1,2]$. At rest, $\mathrm{T}_{\mathrm{C}}$ is regulated largely via controlling blood flow in extremities (and thus $\mathrm{T}_{\mathrm{sk}}$ ); vasodilation strongly predicts reduced vigilance [3] and faster sleep onset[4]. In narcolepsy, high daytime extremity temperatures and a smaller distal-to-proximal gradient (DPG) indicates higher sleep propensity [5]. Cool extremities have been linked observationally to delayed sleep onset in the elderly, and experimentally shown to reduce sleep propensity in narcolepsy [6]. Therefore, the aim of this study was to test the hypothesis that cooling the feet would maintain vigilance during extended wakefulness in healthy adults.
\end{abstract}

\section{Methods}

A randomised cross-over experiment was completed using nine healthy young adult participants with normal sleep patterns. After providing informed consent, and a daytime familiarisation, they undertook three 3-h laboratory sessions in which water-perfused booties were used to provide Mild cooling, Moderate cooling or no cooling (Control). Sessions were in a dimly-lit room, beginning at 2230. Each 30 min consisted of quiet rest interspersed with a 10-min psychomotor vigilance task (PVT), 7-min Karolinska Drowsiness Test (KDT), and ratings of sleepiness, perceived body temperature and thermal discomfort. EEG spectral powers (theta, alpha and beta) were determined within the PVT and KDT. Analyses were by repeated measures ANOVA $(\alpha=0.05)$ with post-hoc contrasts with Bonferroni correction.

\footnotetext{
* Correspondence: jim.cotter@otago.ac.nz

'School of Physical Education, Sport and Exercise Sciences, University of Otago, Dunedin, New Zealand

Full list of author information is available at the end of the article
}

\section{Results}

Foot temperatures in Control and Mild and Moderate cooling averaged $34.5(0.5), 30.8(0.2)$ and $26.4(0.1){ }^{\circ} \mathrm{C}$ (all $P<0.01$ ). Yet, the upper-limb DPG remained stable (at $\left.\sim 0.3{ }^{\circ} \mathrm{C}\right)$ regardless of condition $(P=0.57)$. The decline in $\mathrm{T}_{\mathrm{C}}\left(\sim 0.35{ }^{\circ} \mathrm{C}\right)$ was also unaffected by condition $(P=0.84)$, as was vigilance (interaction for response speed: $P=0.45$ ). A small and transient reduction in sleepiness was evident with cooling $(P=0.046)$; otherwise sleepiness and vigilance deteriorated in conjunction with the fall in $\mathrm{T}_{\mathrm{C}}$ in each condition $(r>0.80)$. Participants felt cooler throughout both cooling trials, but thermal comfort was unaffected $(P=0.43)$, as were almost all EEG parameters during the KDT. All dependent measures were affected by time.

\section{Discussion}

Several lines of evidence implicate a role for distal temperature in declining vigilance in the evening [3-6]. The extent of foot cooling used in the current study was not sufficient to alter natural homeostatic thermal- and sleep-progressions, except for a transient and minor rise in wakefulness. More substantive cooling of the extremities might be required to impact vigilance; by affecting the regulated night-time reduction in $\mathrm{T}_{C}$ or causing a distracting affect from $T_{\text {sk }}$ itself (which would aid wakefulness but may impair cognition).

\section{Conclusion}

In healthy, young adults, $\mathrm{T}_{\mathrm{C}}$ and vigilance decline regardless of mild or moderate cooling of the feet, and any effect on sleepiness is small and transient.

\footnotetext{
Authors' details

${ }^{1}$ School of Physical Education, Sport and Exercise Sciences, University of Otago, Dunedin, New Zealand. ${ }^{2}$ Dunedin School of Medicine, University of Otago, Dunedin, New Zealand.
} 


\section{References}

1. Karasek M, Winczyk K: Melatonin in humans. J Physiol Pharmacol 2006, 57:19-39.

2. Lack $L$, et al: The relationship between insomnia and body temperatures. Sleep Med Rev 2008, 12:307-17.

3. Raymann R, Van Someren E: Time on task impairment of psychomotor vigilance is affected by mild skin warming and changes with aging and insomnia. Sleep 2007, 30:96-103.

4. Krauchi K, et al: Warm feet promote the rapid onset of sleep. Nature 1999, 401(6748):36-37.

5. Fronczek $R$, et al: Altered skin temperature regulation in narcolepsy related to sleep propensity. Sleep 2006, 29:1444-1449.

6. Fronczek R, et al: Manipulation of core body and skin temperature improves vigilance and maintenance of wakefulness in narcolepsy. Sleep 2008, 31:233-240.

doi:10.1186/2046-7648-4-S1-A114

Cite this article as: Sixtus et al: Mild cooling of the feet does not aid night-time vigilance. Extreme Physiology \& Medicine 2015 4(Suppl 1):A114.

\section{Submit your next manuscript to BioMed Central} and take full advantage of:

- Convenient online submission

- Thorough peer review

- No space constraints or color figure charges

- Immediate publication on acceptance

- Inclusion in PubMed, CAS, Scopus and Google Scholar

- Research which is freely available for redistribution

Submit your manuscript at www.biomedcentral.com/submit 